\title{
Remodel While You Work
}

Mr. Harlow is assistant librarian, University of California at Los Angeles.

$\mathrm{R}^{\mathrm{E}}$ EMODELING offers building opportunities and problems similar to those of new construction, except that planning begins with fixed outlines-and the planners are inside. If the old building looks tacky, if its facilities are 20 to 40 years old, or its physical arrangement is outmoded by new developments in service or by recent structural additions, call in the best available advisers on service, building and finance and explore what a remodeling project can do. Unless the existing structure is too tight, erratic or outgrown for satisfactory revision or expansion, it can be revamped to provide new arrangements and working conditions which more nearly comply with modern standards.

Many aspects of beauty and utility are only skin deep. New paint, acoustical treatment and floor covering are obvious surface features. New lighting may well be, unless old wiring is overloaded or substandard. Nonbearing partitions can be removed with little difficulty and new ones erected. New air supplies can be built in. Surplus head room can be furred down, and rooms, corridors, windows and doors can be added or taken away. Old finishings, furnishings and furbishings may be readily restyled or renewed. Such miracles of rehabilitation will raise the spirits of the staff, interest the public and benefit all the operations of the library.

Something of the sort has been done at the University of California at Los Angeles. Attached to a recent appropriation to erect a new wing of the library building was an item to remodel the old structure to adjust it to the resulting changes. Fortunately, construction and reconstruction were not concurrent as planned, but came in sequence, or the disruption of library operations would have been scandalously complete. Building the new wing required 18 months; remodeling, over seven, with a year intervening for planning and bids-a three-year interim of disturbance. Reference here to some of the experiences may not be amiss for members of a notoriously building-conscious profession.

Planning began back in the pre-World War II past, but changed as the library developed under the stimulation of a postwar population surge and the energies of a new library administration. About 1948, plans were cued into a 25-Year Building Program, indicating not only what was immediately needed for sound library operation, but how these units of space, capacity and service fitted into future campus library needs. The occupation of the new wing, and the gradual eviction of nonlibrary users of building space, led up to the Alterations Project, intended to bring the whole library plan up to present needs and standards.

Remodeling procedures are hard to codify, even in retrospect. They do not start with a clean slate or a cleared plot but with so much enclosed area, and it probably is not enough. "Library standards" for buildings ought to be kept conveniently in mind, but they are more suitable to new construction, library literature, 25-year plans, and promotional campaigns. Remodelers need to begin by looking search- 
ingly into present conditions, current operations and existing services.

At U.C.L.A. planning was done by departments, with a coordinator to adjust, unify, arbitrate or make decisions as conditions indicated. Many persons participated, and several sets of departmental studies and layouts were abandoned as the probability of remodeling waxed and waned. So much had circumstances altered cases in the last two years before construction began that a full set of detailed drawings were fortunately canceled and a new set prepared. By that time the general layout of library use and of space had jelled, and the plan seemed wholly logical and sound.

Essential planning should include (I) the study and evaluation of existing facilities, (2) provision for needed new services and (3) the general modernization of equipment and utilities. One should not work too much in the abstract; the general pattern of construction is already set, and remodeling is concerned with making specific adaptations.

\section{Existing Facilities}

A good deal of information about existing dislocations and inadequacies is probably already available or potential in the minds of the staff. Hints of unsatisfactory conditions and ideas for their improvement can often be obtained or checked by discussing existing problems. With staff aid, trace freight and passenger routes through the library, for ease and convenience of flow. Must books travel over devious paths and hurdles from the receiving room door to their roosts in the stack? Are there hitches or complications in the delivery and return of books between shelves and borrowers? Does the public become stranded at certain points or pile up in queues? Instead of being a convenient center of reference and bibliography, does the reference desk become an island or a police kiosk among traffic lanes? Are the arrangement and appearance of inside departments orderly, functional and conducive to efficient, satisfactory work? Systematically check all passages, blocks, work areas, service stations and parking spaces, but avoid getting sidetracked into diverting but endless studies, statistics and surveys.

\section{New Services}

Planned new services or extensions of existing facilities call for the rearrangement of space and the shifting or acquisition of new equipment. Examples of such developments are new undergraduate services; graduate and faculty desks or carrells; inside space for professional staff in public departments; provision for the care and use of rare books, music, government publications and bibliography; listening, smoking and typing rooms; staff quarters; an information desk. The area of a former reading room, vacated offices and classrooms, an abandoned storage area-whatever space can be reclaimed by substitution, exchange or conversion-can be transmuted into virtually any use which is consistent with the over-all traffic and service plan. Attempt to take care of current needs, with a possible margin for expansion, or at least with definite plans for future changes and additions. Alterations should be something more than stopgaps; they should fit directly or eventually into a cumulative program of library development.

\section{Modernization}

Modernization of furnishings, finishings and utilities are periodically in order. New paint, using light colors, chosen imaginatively and with restraint, will bring about the quickest miracle. Most lighting a decade old can be improved with new, adequate fixtures, giving higher intensities, 
better diffusion, less glare and a generally more comfortable and stimulating visual environment. Ample general illumination, instead of strictly local lighting, for reading, work and stack areas should be investigated. The control of outside glare is important to inside lighting, reducing the contrast between window brightness and interior light levels. Likewise, inside extremes should be brought close together. Good general illumination, with light colored and evenly illuminated ceilings, light walls, light but dull finished table tops, a medium to light floor covering, and the screening of outside glare creates an over-all high scale visual pattern which is easy on the eyes, pleasant to the senses and economic of operation, since fewer foot-candles of artificial illumination are needed under such conditions. Well-designed and placed fluorescent units at U.C.L.A. are proving thoroughly satisfactory, in spite of preliminary doubts and fears. Suspended, not flush mounted, they light ceiling as well as floors. One type with hinged Holophane lenses has proven particularly good for offices and public reading room use.

Not devoted to fluorescents for all conditions, a different solution has been found for the library's one monumental reading room. Flush with the surface of its 38 -foot vaulted ceiling are installed banks of mixed incandescent and mercury vapor globes, each light with its separate reflector, with thin, light colored metal louvres beneath. Each of 40 panels contains one 450 -watt mercury vapor globe (Westinghouse EH-I) and two 750-watt incandescent bulbs. And in a central dome are embedded a pattern of recessed spots (R-40) which light without deforming this existing architectural feature. In another area a floodlighted ceiling counteracts the glare of spots and adds to general illumination. Thus a flood of light is provided on reading tables, solving after many years of student criticism and candlelight parades a problem as old as the building itself.

Window glare may be controlled by the common venetian blind, inside or outside louvres, screens of several types, colored glass or plastic filters (such as Plexiglass), or by one of the several kinds of glass which bend, absorb or shield light rays when viewed from predetermined angles. The filter principle (with colors in the blues, greens and browns) gives the most natural appearance, avoiding the dark or opaque effects produced by most types of control.

Acoustical treatment of reading and working areas gives the auditory system a treat similar to that provided for the eyes by balanced lighting. Acoustical tile is probably the easiest type to apply to existing space, and its effects are truly marvelous. Air conditioning units can be installed in new "fan" rooms to correct specific situations (forced air, warmed and filtered, is the least expensive type, with humidity control and refrigeration additional). New floor coverings (asphalt tile, linoleum, rubber tile and cork, the most common materials), new counter and table tops, modernized plumbing, adequate electrical service outlets and switching, intercommunication systems, new furniture, unit steel shelving and countless other latter day inventions offer unending possibilities. New doors, walls, ceilings or mezzanine construction should not be overlooked during planning.

Early in the initial study and planning period an architect and engineer should be brought into the program, since they can provide both preventative and curative assistance. In addition to their special technical knowledge, their knack, experience and training can very often provide better solutions to problems recognized and presented by the librarian than can the librar- 
ian himself. And of course the finished drawings, specifications and standards are prepared by them. But the plans, particularly those showing the layout of space and the location of electrical and mechanical features, should be gone over inch by inch by a knowledgeable member of the library staff. He should investigate the adequacy of lighting to fit general or special requirements; the presence of electrical outlets for reaching machines, erasers, playing equipment, clocks and typewriters; the convenience of switches for the control of light (enclosed panel controls for most fluorescents); the existence of drinking fountains and wash basins; and of telephones for staff and public use; the proper linear space for standard shelving and furniture; the precise heights of counters and tables, with space below for knees or shelving; the placement and swing of doors for best traffic use and economy of wall space; the setting up of control points for library materials and of an adequate keying system; the provision of directional signs; and the omission of nonessential items. The architect will be sure to provide proper stairways, public toilets, janitors' closets, mechanical areas and other facilities essential for normal circulation, building maintenance and emergencies. Fortunate is the librarian who has (as at U.C.L.A.) a competent and cooperative Office of Architects \& Engineers at his beck and call.

Specifications should incorporate standards for materials and construction, citing acceptable brands or equivalents, when they exist. Remodeling may need to be scheduled in two or more successive stages, in order not to disrupt library service too seriously, and a statement of these limitations should be included. To guard against having the low bid in excess of available funds, the specifications may designate a basic unit of material and construction, with an addendum of items to be bid upon as alternates. That part of the total project which can be encompassed by the existing budget can then be authorized without canceling all of the bids and starting again. Units of lighting, acoustical treatment, flooring, certain plumbing items or work on some designated area of the building may comprise alternates. Bids may be aimed at a general contractor who sublets services and materials and includes subcontractors' bids in his total estimate; or the project may be divided into construction and materials or into general construction, mechanical and electrical work, or in other ways. A general contractor will find it necessary to add a margin of cost for imponderables. If the contract does not go to a general contractor, the institution must face the responsibility for the delivery of materials and for the integration of the several construction operations, and it will have to pay the penalties for delays and duplication.

With the beginning of construction, the real period of travail sets in. A member of the library staff, presumably the building coordinator, should follow the project closely, working intimately with the inspectors provided by the institution and architects. Errors and omissions in the original plans will appear, and he should point out his discoveries and have them corrected if possible. He should make advance arrangements for shifts of people and material and see them carried out on schedule. This will likely be the cause of greatest discomfort and confusion, and he will need 'a limited amount of emergency authority over library operations in order to assure complete coordination of workmen and staff. Detailed plans and maps of moves may be required for the guidance of workmen. Special attention should be given to publicizing the remodeling project in advance (Continued on page 252) 
man and the American concept, historically represented by the influential personalities of Cutter and Dziatzko, the real core of the international unification problem. The Czechoslovakian report recognizes fully the thoroughness and logical consistency of the Pr. I., but emphasizes the usefulness of corporate authorship, especially taking into consideration the enormous increase of "anonymous" publications.

It is clear that a fundamental prerequisite for an international code of cataloging rules is national unification of cataloging practice. In many countries there is still considerable inconsistency and diversity between the different types of libraries and sometimes between linguistic groups. But the progress in national codification may and should be accompanied by efforts to promote international unification. It is up to the International Federation of Library Associations to attack the main problems which are sketchily outlined in this article with energy and with the optimistic feeling that in spite of all obstacles the final target will be reached and will work out to the benefit of all.

\section{Remodel While You Work}

(Continued from page 236)

and during operations in order to adjust the minds of the public and staff to the extraordinary conditions prevailing. In due time, preparations to reoccupy the refinished building should be made in some detail, to proceed by department or section, perhaps as construction work is completed. A celebration by staff, public and friends might well signalize the termination of the alterations work or of a particularly significant portion of it (such as a rare book room or an undergraduate library). It would mark the cessation of a particularly difficult and trying experience and might open a new era in library history.

It is difficult to anticipate the contingencies which may arise while revising and adding to existing construction. For this reason remodeling is less sought by building contractors than is new construction, and if revisions are to be very comprehensive, unit costs may run higher than for new work. Extensive alterations during occupancy are disadvantageous both to contractor and librarians, and the most workable compromise should be made between normal library function and the complete abandonment of the building to plasterers, painters and plumbers.

Remodeling calls for careful, creative planning, adequate funding, meticulous coordination and limitless reserves of staff good will and endurance. But if the old building is to continue as a modern library, an educational force and research center, and as a workshop for an inspired library staff, it must be continuously reshaped in the image of that fleeting goal, ideal function, and of that evanescent measure of good and beauty, our hearts' desire. 